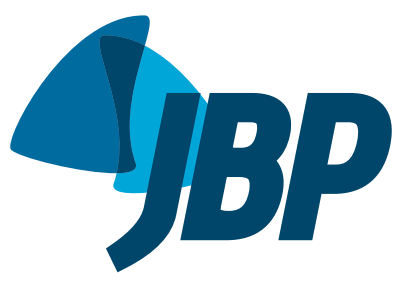

1. Hospital Alberto Rassi-Hospital Geral de Goiânia, Goiânia (GO) Brasil.

2. Programa de Pós-Graduação em Ciências da Saúde, Universidade Federal de Goiás, Goiânia (GO) Brasil.

3. Faculdade de Medicina, Universidade Federal de Goiás, Goiânia (GO) Brasil.

4. Clínica do Aparelho Respiratório, Goiânia (GO) Brasil.

Submitted: 29 September 2015.

Accepted: 9 May 2016

Study carried out at Clínica do Aparelho Respiratório and Hospital Alberto RassiHospital Geral de Goiânia, Goiânia, Brazil.

\section{STOP-Bang questionnaire: translation to Portuguese and cross-cultural adaptation for use in Brazil}

\author{
Lorena Barbosa de Moraes Fonseca ${ }^{1,2}$, Erika Aparecida Silveira ${ }^{2,3}$,
} Nathalia Meireles Lima ${ }^{3}$, Marcelo Fouad Rabahi ${ }^{1,2,3,4}$

\begin{abstract}
Objective: To translate and perform a cross-cultural adaptation of the Snoring, Tiredness, Observed apnea, high blood Pressure, Body mass index, Age, Neck circumference, and Gender (STOP-Bang) questionnaire so that it can be used as a screening tool for the diagnosis of obstructive sleep apnea in Brazil. Methods: Based on the principles of good practice for the translation and cross-cultural adaptation of such instruments, the protocol included the following steps: acquisition of authorization from the lead author of the original questionnaire; translation of the instrument to Brazilian Portuguese, carried out by two translators; reconciliation; back-translation to English, carried out by two English teachers who are fluent in Portuguese; review of the back-translation; harmonization; review and approval of the questionnaire by the original author; cognitive debriefing involving 14 patients who completed the questionnaire; analysis of the results; and review and preparation of the final version of the instrument approved by the review committee. Results: The final version of the STOP-Bang questionnaire for use in Brazil showed a clarity score $>9$ (on a scale of 1-10) for all of the questions. The Cronbach's alpha coefficient was 0.62 , demonstrating the internal consistency of the instrument. The means and standard deviations of the age, body mass index, and neck circumference of the patients studied were $46.8 \pm 11.2$ years, $43.7 \pm 8.5 \mathrm{~kg} / \mathrm{m}^{2}$, and $41.3 \pm 3.6 \mathrm{~cm}$, respectively. Conclusions: The STOP-Bang questionnaire proved to be understandable, clear, and applicable. The original instrument and the translated version, cross-culturally adapted for use in Brazil, were consistently equivalent. Therefore, it can become a widely used screening tool for patients with suspected obstructive sleep apnea.
\end{abstract}

Keywords: Sleep apnea, obstructive; Questionnaires; Translations.

\section{INTRODUCTION}

Obstructive sleep apnea (OSA) is a sleep disorder characterized by repeated interruption of ventilation during sleep caused by upper airway closure. ${ }^{(1)}$ Studies have shown that, even when asymptomatic, OSA is independently associated with increased morbidity and mortality. ${ }^{(2-4)}$ It has been estimated that moderate to severe OSA goes undiagnosed in approximately $80 \%$ of males and $93 \%$ of females. ${ }^{(5,6)}$

A major obstacle to the diagnosis of OSA is that polysomnography, which is the gold standard for diagnosis, is time-consuming and expensive, and there are not enough sleep medicine specialists. ${ }^{(1)}$ Various screening tests have been developed. Such tests are aimed at identifying patients at high risk for OSA-all of whom should undergo sleep studies-and low-risk patients, thus avoiding unnecessary tests. ${ }^{(1,7-11)}$ Questionnaires have been shown to be adequate screening instruments, given that they are easily applied and are part of routine medical practice. ${ }^{(12)}$

Various questionnaires have been developed/ validated for that purpose, including the Wisconsin
Sleep Questionnaire, the Apnea Score, a questionnaire developed by Haraldsson et al., the Sleep Apnea of Sleep Disorders Questionnaire, the American Society of Anesthesiologists checklist, the Berlin questionnaire (BQ), the Snoring, Tiredness, Observed apnea, and high blood Pressure (STOP) questionnaire, and the STOP-Body mass index, Age, Neck circumference, and Gender (Bang) questionnaire. ${ }^{(11)}$

For predicting the presence of moderate to severe OSA, the $B Q$ and the STOP-Bang questionnaire have been found to have the highest sensitivity and specificity, respectively. The $\mathrm{BQ}$, however, has a large number of questions and a complicated scoring system. ${ }^{(13)}$

The STOP questionnaire and the STOP-Bang questionnaire have greater methodological validity, with reasonable accuracy, and features that are easy to use and remember. Because it is more comprehensive, the STOP-Bang questionnaire is the preferred instrument, ${ }^{(11)}$ having been developed and validated as an English-language screening tool for OSA in surgical patients. ${ }^{(14)}$

The STOP-Bang questionnaire is a very practical instrument because it is concise, is apparently easy to 
memorize, has a simple scoring system, and requires only a few minutes to be completed. . $^{(1,15,16)}$ It consists of eight questions regarding snoring, tiredness/ fatigue/sleepiness, observed apnea during sleep, blood pressure, body mass index (BMI), age, neck circumference, and gender. ${ }^{(14)}$ The questions can be answered affirmatively ("yes", 1 point) or negatively ("no", 0 points), the total score ranging from 0 to 8.

The present study is relevant because the STOP-Bang questionnaire had yet to be translated to Portuguese and culturally adapted for use in Brazil. Therefore, the objective of the present study was to translate and perform a cross-cultural adaptation of the STOP-Bang questionnaire so that it can be used as a screening tool for the diagnosis of OSA in Brazil.

\section{METHODS}

The present study was approved by the Research Ethics Committee of Hospital Alberto Rassi-Hospital Geral de Goiânia, located in the city of Goiânia, Brazil. Before completing the questionnaire, all patients gave written informed consent.

Based on the principles of good practice for the translation and cross-cultural adaptation of such instruments established by Wild et al., ${ }^{(17)}$ Guillemin et al.,(18) and Beaton et al.,(19) the protocol included the following steps (Figure 1 ):

1. Preparation: The lead author of the STOP-Bang questionnaire was initially contacted. The University Health Network, which owns the copyright of the STOP-Bang questionnaire, granted a license for use of the instrument.

2. Translation: The original, English-language version of the STOP-Bang questionnaire was translated to Brazilian Portuguese by two pulmonologists residing in Brazil and fluent in English. They translated the questionnaire independently. Both sought to translate it conceptually rather than literally.

3. Reconciliation: The review committee, which consisted of four pulmonologists (including the two translators, the project coordinator, and a sleep medicine specialist), compared the two translations. The most appropriate version was arrived at by consensus, being designated Version 1 of the STOP-Bang questionnaire for use in Brazil.

4. Back-translation to English: Version 1 of the STOP-Bang questionnaire for use in Brazil was back-translated to English, which is the language in which the STOP-Bang questionnaire was originally written. Version 1 of the STOP-Bang questionnaire for use in Brazil was back-translated to English by two English teachers originally from English-speaking countries and fluent in Portuguese. Neither had access to the original version of the STOP-Bang questionnaire, and both were instructed to perform a literal translation.

5. Review of the back-translation: The review committee compared the two back-translations to ensure their conceptual equivalence.
6. Harmonization: The review committee compared the two back-translations to English with the original questionnaire to determine whether there were any discrepancies and thus ensure that the translated version was consistent with the original instrument. Version 2 of the STOP-Bang questionnaire for use in Brazil was thus arrived at.

7. Review and approval of the questionnaire by the original author: After harmonization, the Brazilian Portuguese version of the STOP-Bang questionnaire and the back-translation to English were submitted to the original author for consideration, as initially requested by the author. The back-translation was fully approved, no modifications being required.

8. Cognitive debriefing: The objective of this step was to determine the clarity, understandability, and acceptability of the translated questionnaire in the target population. An attempt was made to identify problematic questions in order to improve understanding and reduce uncertainty among respondents. The Brazilian Portuguese version of the STOP-Bang questionnaire was administered to a group of 14 patients by the principal investigator. Of those 14 patients, 7 were selected from among those treated at a private clinic in the city of Goiânia (Clínica do Aparelho Respiratório) and 7 were selected from among those treated at a public outpatient clinic (Hospital Alberto Rassi-Hospital Geral de Goiânia Pulmonology Outpatient Clinic), also in the city of Goiânia. During medical visits at each facility, patients were invited to participate in the study, and, for each facility, a decision was made to include the first 7 patients who agreed to participate. Based on the principles of good practice for the translation and cross-cultural adaptation of such instruments established by Wild et al., ${ }^{(17)}$ according to whom cognitive debriefing is satisfactory when 5-8 individuals are involved, we decided to include 7 patients from each facility, a total of 14 patients having therefore participated in the cognitive debriefing step of the protocol. Patients were eligible to participate in the cognitive debriefing step of the cross-cultural adaptation protocol if they were 18 years of age or older and had clinical complaints suggestive of OSA, including excessive daytime sleepiness, nonrestorative sleep, fatigue, insomnia, gasping or choking during sleep, snoring, and witnessed apneas. (20) Patients were excluded if they were unable to read, sign, or understand the informed consent form. Questions related to categorical data were read and answered by the participants, whereas numerical data (i.e., age, weight, and height for calculating the BMI and neck circumference) were recorded by the examiner after measurement. All items were read by all participants so that they were able to determine how clear each item was. Body weight (in $\mathrm{kg}$ ) was measured with a digital scale (Welmy S.A., Santa Bárbara do Oeste, Brazil), the capacity and precision of which were $200 \mathrm{~kg}$ and $100 \mathrm{~g}$, respectively. Height (in $\mathrm{m}$ ) was measured with a stadiometer attached to the scale (capacity of $2 \mathrm{~m}$, graduated in $\mathrm{cm}$ ). Participants stood erect, barefoot and wearing light clothing, with 


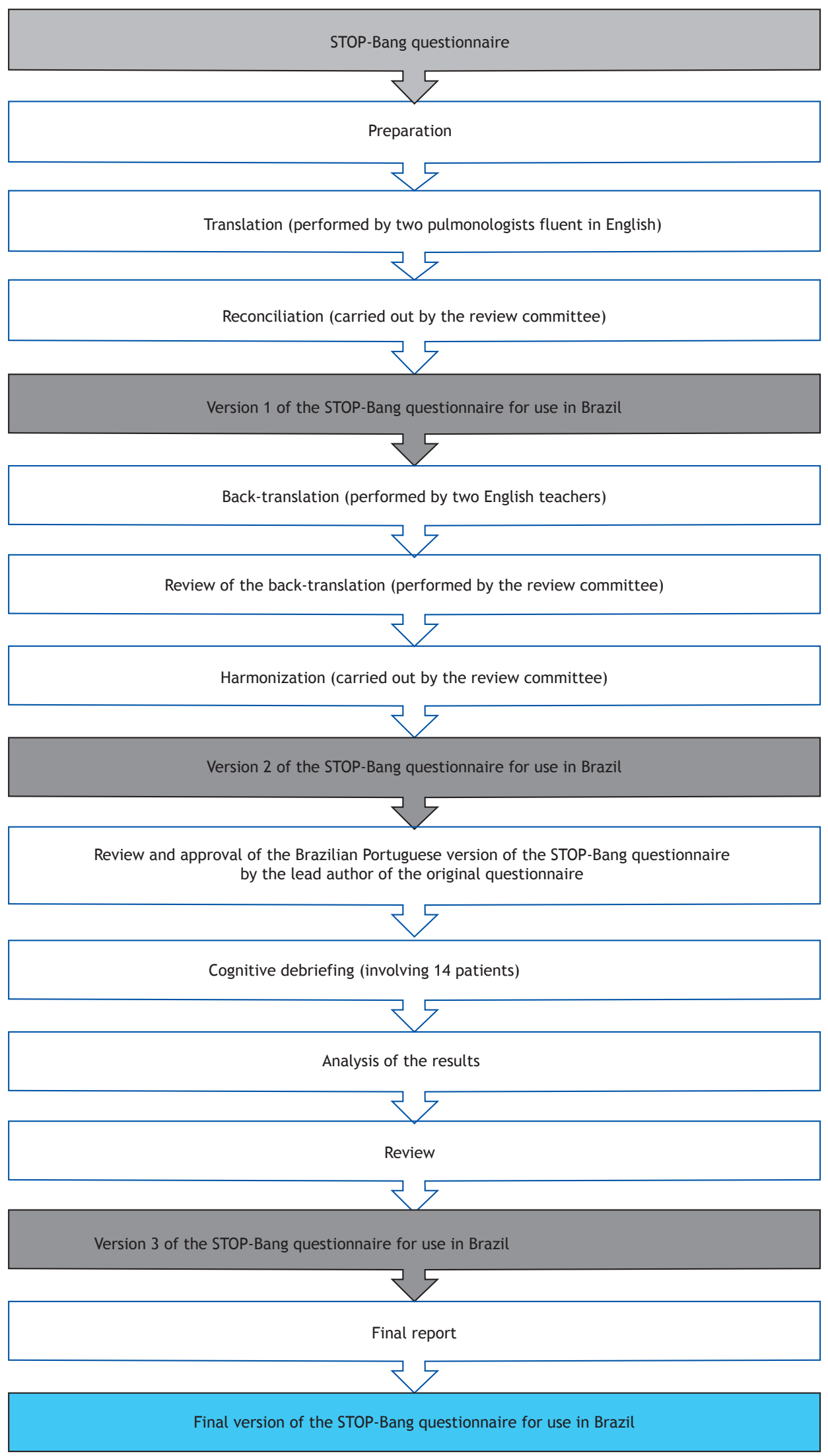

Figure 1. Flowchart of the translation and cross-cultural adaptation of the STOP-Bang questionnaire for use in Brazil. 
their arms relaxed at their sides and their heels together. The BMI was calculated as weight in kilograms divided by height in meters squared. ${ }^{(21)}$ Neck circumference was measured to the nearest $0.01 \mathrm{~cm}$ with an inelastic tape measure of 150 $\mathrm{cm}$ in length. Neck circumference was measured at the laryngeal prominence level. The laryngeal prominence is popularly known as "Adam's apple" and is a protrusion of the thyroid cartilage, which lies below the hyoid bone and nearly encircles the larynx. This was chosen as a point of reference on the basis of the measurements used in the original STOP-Bang questionnaire. ${ }^{(14)}$ A clarity questionnaire was used in order to evaluate patient understanding and acceptance of each question. An interval scale, with scores ranging from 1 to 10 , was used in order to assess the clarity of each question. Scores ranging from 1 to 4 indicated that the question was confusing; scores ranging from 5 to 7 indicated that the question was unclear; and scores ranging from 8 to 10 indicated that the question was clear. ${ }^{(22,23)}$ The clarity score was calculated as the arithmetic mean of the scores given by patients. A clarity score of $<4$ indicated that the question had to be replaced; a clarity score of $<8$ indicated that the question had to be reworded; and a clarity score $\geq 8$ indicated that the question was sufficiently clear. ${ }^{(23,24)}$ Participants were allowed to write, below each question, a comment on the interpretation and clarity of the question if they so wished. (23) The clarity scores and comments from patients showed that there was no need to modify the questionnaire. Cronbach's alpha coefficient was used in order to assess the reliability of the Brazilian Portuguese version of the STOP-Bang questionnaire. ${ }^{(25)}$

9. Analysis of the results of cognitive debriefing and conclusion: Patient interpretation was compared with the original version of the questionnaire to determine whether there were any discrepancies. The analysis showed that no modifications were required. The project coordinator performed the analysis. Data analysis was performed with the Stata statistical software package, version 12.0 (StataCorp LP, College Station, TX, USA). The distribution of continuous variables was expressed as mean and standard deviation. For categorical variables, absolute and relative frequencies were calculated.

10. Review: The review step consisted of a final evaluation of the translated questionnaire. The translated questionnaire was carefully reviewed by two of the pulmonologists in the review committee and a Portuguese teacher, their objectives being to perform a final evaluation of the translation and correct any misspellings or grammatical errors. Version 3 of the STOP-Bang questionnaire for use in Brazil was thus arrived at.

11. Final report: A final report was written in order to document the process of translation and cross-cultural adaptation of the STOP-Bang questionnaire and disseminate the final version of the questionnaire for use in Brazil. The present article originated from that document.

\section{RESULTS}

In the reconciliation step of the translation of the STOP-Bang questionnaire, the review committee decided to make two adjustments. Although the word "Tired" in the second question in the original questionnaire was translated as "cansado" by both translators, the review committee decided to use the term "faTigado" instead, which also appears in the question. This allowed us to maintain the acronym STOP-Bang, by which the questionnaire is known worldwide. For the same reason, a decision was made to use the term "circuNferência de pescoço" instead of "tamanho grande de pescoço" in the seventh question, the former also being deemed more appropriate than the latter. The same was true for the term "circunferência cervical", which appears in the seventh question as well and was deemed more appropriate than "colarinho de camisa".

In the harmonization step of the protocol, the review committee reached a consensus that it would be clearer for patients if response options "yes" and "no" appeared after rather than before the question (i.e., at the end of the sentence rather than at the beginning).

The lead author of the STOP-Bang questionnaire, who represented the group of authors of the original questionnaire, made no objections and fully approved the aforementioned adaptations.

In the cognitive debriefing step of the protocol, 14 patients were interviewed. Of those, 7 were selected from among those treated at a public pulmonology outpatient clinic and 7 were selected from among those treated at a private pulmonology clinic. All patients interviewed were literate. Of those who had been selected from among those treated at a public outpatient clinic, none had a college degree. Of those who had been selected from among those treated at a private clinic, 2 had a college degree (one in advertising and one in nursing). The invitation to participate in the study was standardized. A decision was made to interview the first 14 patients (7 at each clinic) who presented with complaints of OSA and agreed to participate in the study. A total of 2 males and 12 females were interviewed. The mean age of the patients was 46.8 \pm 11.2 years (range, $30-71$ years). Only 2 were over 65 years of age, and they had good judgment and good cognitive function. The mean BMI was $43.7 \pm$ $8.5 \mathrm{~kg} / \mathrm{m}^{2}$ (range, $29.6-60.0 \mathrm{~kg} / \mathrm{m}^{2}$ ), and the mean neck circumference was $41.3 \pm 3.6 \mathrm{~cm}$ (range, 37-47 $\mathrm{cm}$; Table 1). All patients interviewed completed all evaluation items.

Mean clarity scores ranged from 9.1 to 9.8 . None of the patients wrote any comments on the interpretation and clarity of the questions; this constitutes evidence that the questions were deemed clear by most of the patients (Table 2).

In the final review step of the protocol, the review committee and a Portuguese teacher found some minor grammatical errors, all of which were corrected. 
The final version of the STOP-Bang questionnaire for use in Brazil incorporated all of the aforementioned modifications (Figure 2).

Among the 14 patients who completed the STOPBang questionnaire in the cognitive debriefing step of the cross-cultural adaptation process, the highest numbers of affirmative answers were related to the presence of high blood pressure (in 11 patients) and loud snoring (also in 11), followed by observed apnea (in 9) and fatigue (in 8; Table 3).

The Cronbach's alpha coefficient was 0.62 , demonstrating the internal consistency of the instrument. Values between 0.60 and 0.80 are considered good for an exploratory study, showing that the data are reliable and that the instrument is of good quality for interpretation. ${ }^{(25)}$

\section{DISCUSSION}

In the present study, the STOP-Bang questionnaire, an instrument used in order to assess the risk of developing OSA, was translated to Portuguese and adapted for use in Brazil.

Table 1. Characteristics of the sample of patients $(\mathrm{N}=14)$ who participated in the cognitive debriefing of the Brazilian Portuguese version of the STOP-Bang questionnaire at a public hospital and a private clinic in the city of Goiânia, Brazil.a

\begin{tabular}{lc}
\multicolumn{1}{c}{ Characteristic } & Result \\
Gender & \\
$\quad$ Male & $2(14.3)$ \\
Female & $12(85.7)$ \\
Place of treatment & \\
$\quad$ Private clinic & $7(50.0)$ \\
$\quad$ Public hospital & $7(50.0)$ \\
Level of education & \\
$\quad$ Elementary school & $7(50.0)$ \\
High school & $5(35.7)$ \\
College & $2(14.3)$ \\
Age, years & $46.8 \pm 11.2$ \\
Body mass index, $\mathrm{kg} / \mathrm{m}^{2}$ & $43.7 \pm 8.5$ \\
Neck circumference, $\mathrm{cm}$ & $41.3 \pm 3.6$ \\
\hline
\end{tabular}

aValues expressed as $\mathrm{n}(\%)$ or mean $\pm \mathrm{SD}$.

Table 2. Clarity of the questions in the Brazilian Portuguese version of the STOP-Bang questionnaire, according to the study participants $(\mathrm{N}=14){ }^{\text {a }}$

\begin{tabular}{lccc}
\multicolumn{1}{c}{ Question } & Clear & Unclear & Confusing \\
1 (roncoS) & $14(100.0)$ & $0(0.0)$ & $0(0.0)$ \\
2 (faTigado) & $14(100.0)$ & $0(0.0)$ & $0(0.0)$ \\
3 (Observado) & $14(100.0)$ & $0(0.0)$ & $0(0.0)$ \\
4 (Pressão) & $14(100.0)$ & $0(0.0)$ & $0(0.0)$ \\
5 (oBesidade) & $13(92.9)$ & $0(0.0)$ & $1(7.1)$ \\
6 (idAde) & $13(92.9)$ & $1(7.1)$ & $0(0.0)$ \\
7 (circuNferência & $14(100.00)$ & $0(0.0)$ & $0(0.0)$ \\
do pescoço) & & & \\
8 (Gênero) & $14(100.00)$ & $0(0.0)$ & $0(0.0)$ \\
\hline alues expressed as $\mathrm{n}(\%)$. & &
\end{tabular}

In the present study, we followed the principles of good practice for the translation and cross-cultural adaptation of such instruments. The methodology employed in our study was based on established guidelines. The process of cross-cultural adaptation of an instrument is complex and involves more than just a simple translation. ${ }^{(26)}$ We followed all of the procedures required in order to achieve semantic, experimental, and conceptual equivalence between the original questionnaire and the translated version, thus ensuring that the resulting instrument is fully adapted to the local culture. We thus sought to ensure that the psychometric properties of the questionnaire were maintained for subsequent instrument validation.

The process of cross-culturally adapting an existing instrument is faster, cheaper, and more efficient than is that of developing a new instrument. In addition, the data obtained locally can be compared with international data. ${ }^{(27)}$

Because of the relatively high prevalence of undiagnosed OSA and its short- and long-term complications, ${ }^{(5,6)}$ a reliable screening tool is needed for rapid prediction of OSA. The STOP-Bang questionnaire was developed and validated for that purpose, being initially aimed at surgical patients. The STOP-Bang questionnaire was based on the $B Q$, which, after being condensed and modified, resulted in the STOP questionnaire. ${ }^{(28)}$

The STOP-Bang questionnaire is currently used worldwide in order to screen patients for OSA. It has been translated in several countries, including Portugal, ${ }^{(12)}$ China, ${ }^{(29)}$ Denmark, ${ }^{(30)}$ Iran, ${ }^{(31)}$ and Saudi Arabia. ${ }^{(32)}$

It is known that there are long waiting lists for polysomnography in most sleep medicine clinics in Brazil. Therefore, the use of screening tools, such as the STOP-Bang questionnaire, appears to be an interesting approach to determine which patients should undergo this screening test for OSA on the basis of the probability of a positive result.

Analysis of the data obtained by using the STOPBang questionnaire can provide physicians with a set of predictive parameters to determine the severity of OSA, serving as a valuable guide for diagnostic or therapeutic decisions. ${ }^{(12)}$

The STOP-Bang questionnaire for use in Brazil is also important for future clinical studies conducted in the country, allowing comparisons between the results obtained and those of studies conducted in other countries. ${ }^{(33)}$

One of the limitations of the present study is that most of the patients were female; this was due to the fact that there were many preoperative evaluations for bariatric surgery at the two clinics included in the present study.

In the present study, the STOP-Bang questionnaire was translated to Portuguese and adapted for use in 
Brazil. The Brazilian Portuguese version of the STOPBang questionnaire proved to be easy to understand, clear, and applicable, the original instrument and the translated version being consistently equivalent. It is therefore recommended that the Brazilian Portuguese version of the STOP-Bang questionnaire be used in order to screen patients for OSA so as to optimize diagnosis and reduce waiting lists for polysomnography. After this initial step, the Brazilian Portuguese version of the STOP-Bang questionnaire can be validated and be quite useful in public health care facilities and private clinics, as well as contributing to clinical research into OSA.

\section{ACKNOWLEDGMENTS}

We would like to thank Dr. Frances Chung, who developed and validated the STOP-Bang questionnaire, for her kindness and for allowing us to translate the questionnaire to Portuguese and adapt it for use in Brazil.

We would also like to thank all colleagues and teachers who participated in the translation, back-translation, and review steps of the cross-cultural adaptation process.

Finally, we would like to thank all Clínica do Aparelho Respiratório and Hospital Alberto Rassi-Hospital Geral de Goiânia patients who contributed to the cross-cultural adaptation of the original questionnaire.

\section{QUESTIONÁRIO STOP-Bang}

\section{- roncos?}

Você ronca alto (alto o bastante para ser ouvido através de portas fechadas ou seu parceiro cutuca você por roncar à noite)?

( ) Sim ( ) Não

\section{- faTigado?}

Você frequentemente sente-se cansado, fatigado ou sonolento durante o dia (por exemplo, adormecendo enquanto dirige)?

( ) Sim ( ) Não

\section{- Observado?}

Alguém já observou você parar de respirar ou engasgando/sufocando durante o sono?

( ) Sim ( ) Não

\section{- Pressão?}

Você tem ou está sendo tratado por pressão alta? ( ) $\operatorname{Sim}($ ) Não

\author{
- oBesidade com índice de massa corporal (IMC) \\ maior que $35 \mathrm{~kg} / \mathrm{m}^{2}$ ? \\ Índice de massa corporal (IMC) maior que \\ $35 \mathrm{~kg} / \mathrm{m}^{2}$ ? \\ ( ) Sim ( ) Não \\ - IdAde \\ Idade maior que 50 anos? \\ ( ) $\operatorname{Sim}($ ) Não \\ - circuNferência de Pescoço \\ (medida na altura do "pomo-de-adão") \\ Para homens: circunferência cervical, maior ou igual \\ a $43 \mathrm{~cm}$. \\ Para mulheres: circunferência cervical maior ou igual \\ a $41 \mathrm{~cm}$. \\ ( ) $\operatorname{Sim}($ ) Não \\ - Gênero \\ Sexo masculino? \\ ( ) $\operatorname{Sim}($ ) Não
}

Critérios de pontuação para a população geral:

- $\quad$ Baixo risco de apneia obstrutiva do sono (AOS): Sim para 0-2 questões

- Intermediário risco de AOS: Sim para 3-4 questões

- $\quad$ Alto risco de AOS: Sim para 5-8 questões

ou "Sim" para 2 ou mais das 4 questões iniciais (STOP) + gênero masculino

ou "Sim" para 2 ou mais das 4 questões iniciais (STOP) + IMC > $35 \mathrm{~kg} / \mathrm{m}^{2}$

ou "Sim" para 2 ou mais das 4 questões iniciais (STOP) + circunferência cervical $\geq 43 \mathrm{~cm}$ para homens ou $\geq$ $41 \mathrm{~cm}$ para mulheres

Figure 2. Final version of the STOP-Bang questionnaire for use in Brazil.

Table 3. Affirmative answers to the questions in the Brazilian Portuguese version of the STOP-Bang questionnaire $(N=14)$. $^{\mathrm{a}}$

\begin{tabular}{lc}
\multicolumn{1}{c}{ Question } & Affirmative answers \\
S: Você ronca alto? & $11(78.6)$ \\
T: Você frequentemente sente-se cansado, fatigado ou sonolento durante o dia? & $8(57.1)$ \\
O: Alguém já observou você parar de respirar ou engasgando/sufocando durante o sono? & $9(64.3)$ \\
P: Você tem, ou está sendo tratado por pressão alta? & $11(78.6)$ \\
B: IMC $>35 \mathrm{~kg} / \mathrm{m}^{2}$ ? & $12(85.7)$ \\
A: Idade $>50$ anos? & $3(21.4)$ \\
N: Circunferência cervical $\geq 43 \mathrm{~cm}$ em homens ou $\geq 41 \mathrm{~cm}$ em mulheres? & $6(42.9)$ \\
G: Sexo masculino? & $2(14.3)$ \\
\hline
\end{tabular}

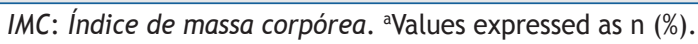




\section{REFERENCES}

1. Boynton G, Vahabzadeh A, Hammoud S, Ruzicka DL, Chervin RD. Validation of the STOP-BANG Questionnaire among Patients Referred for Suspected Obstructive Sleep Apnea. J Sleep Disord Treat Care. 2013;2(4). http://dx.doi.org/10.4172/2325-9639.1000121

2. Chung F, Subramanyam R, Liao P, Sasaki E, Shapiro C, Sun Y. High STOP-Bang score indicates a high probability of obstructive sleep apnoea. Br J Anaesth. 2012;108(5):768-75. http://dx.doi.org/10.1093/ bja/aes022

3. Young T, Finn L, Peppard PE, Szklo-Coxe M, Austin D, Nieto FJ, et al. Sleep disordered breathing and mortality: eighteen-year follow-up of the Wisconsin sleep cohort. Sleep. 2008; 31(8):1071-8.

4. Marshall NS, Wong KK, Liu PY, Cullen SR, Knuiman MW, Grunstein RR. Sleep apnea as an independent risk factor for all cause mortality: the Busselton Health Study. Sleep. 2008;31(8):1079-85.

5. Chung F, Yang $Y$, Brown R, Liao P. Alternative scoring models of STOP-bang questionnaire improve specificity to detect undiagnosed obstructive sleep apnea. J Clin Sleep Med. 2014;10(9):951-8. http:// dx.doi.org/10.5664/jcsm.4022

6. Young T, Evans L, Finn L, Palta M. Estimation of the clinically diagnosed proportion of sleep apnea syndrome in middle-aged men and women. Sleep. 1997;20(9):705-6.

7. Flemons WW, Whitelaw WA, Brant R, Remmers JE. Likelihood ratios for a sleep apnea clinical prediction rule. Am J Respir Crit Care Med. 1994; 150(5 Pt 1):1279-85. http://dx.doi.org/10.1164/ ajrccm.150.5.7952553

8. Kump K, Whalen C, Tishler PV, Browner I, Ferrette V, Strohl KP, et al. Assessment of the validity and utility of a sleep-symptom questionnaire. Am J Respir Crit Care Med. 1994;150(3):735-41. http://dx.doi.org/10.1164/ajrccm.150.3.8087345

9. Maislin G, Pack Al, Kribbs NB, Smith PL, Schwartz AR, Kline LR, et al. A survey screen for prediction of apnea. Sleep. 1995;18(3):158-66.

10. Viner S, Szalai JP, Hoffstein V. Are history and physical examination a good screening test for sleep apnea? Ann Intern Med. 1991;115(5):356-9. http://dx.doi.org/10.7326/0003-4819-115-5-356

11. Abrishami A, Khajehdehi A, Chung F. A systematic review of screening questionnaires for obstructive sleep apnea. Can J Anaesth. 2010;57(5):423-38. http://dx.doi.org/10.1007/s12630-010-9280-x

12. Reis R, Teixeira F, Martins V, Sousa L, Batata L, Santos C, et al. Validation of a Portuguese version of the STOP-Bang questionnaire as a screening tool for obstructive sleep apnea: Analysis in a sleep clinic. Rev Port Pneumol (2006). 2015;21(2):61-8. http://dx.doi. org/10.1016/j.rppnen.2014.04.009

13. Chung F, Elsaid H. Screening for obstructive sleep apnea before surgery: why is it important? Curr Opin Anaesthesiol, 2009;22(3):40511. http://dx.doi.org/10.1097/ACO.0b013e32832a96e2

14. Chung F, Yegneswaran B, Liao $P$, Chung SA, Vairavanathan $S$, Islam $S$, et al. STOP questionnaire: a tool to screen patients for obstructive sleep apnea. Anesthesiology. 2008;108(5):812-21. http://dx.doi. org/10.1097/ALN.0b013e31816d83e4

15. Farney RJ, Walker BS, Farney RM, Snow GL, Walker JM. The STOPBang equivalent model and prediction of severity of obstructive sleep apnea: relation to polysomnographic measurements of the apnea/ hypopnea index. J Clin Sleep Med. 2011;7(5):459-65B. http://dx.doi. org/10.5664/jcsm.1306

16. Vasu TS, Doghramji K, Cavallazzi R, Grewal R, Hirani A, Leiby B, et al. Obstructive sleep apnea syndrome and postoperative complications: clinical use of the STOP-BANG questionnaire. Arch Otolaryngo Head Neck Surg. 2010;136(10):1020-4. http://dx.doi.org/10.1001/ archoto.2010.1020

17. Wild D, Grove A, Martin M, Eremenco S, McElroy S, VerjeeLorenz A, et al. Principles of Good Practice for the Translation and
Cultural Adaptation Process for Patient-Reported Outcomes (PRO) Measures: report of the ISPOR Task Force for Translation and Cultural Adaptation. Value Health. 2005;8(2):94-104. http://dx.doi. org/10.1111/j.1524-4733.2005.04054.x

18. Guillemin F, Bombardier C, Beaton D. Cross-cultural adaptation of health-related quality of life measures: literature review and proposed guidelines. J Clin Epidemiol. 1993;46(12):1417-32. http:// dx.doi.org/10.1016/0895-4356(93)90142-N

19. Beaton DE, Bombardier C, Guillemin F, Ferraz MB. Guidelines for the process of cross-cultural adaptation of self-report measures. Spine (Phila Pa 1976). 2000;25(24):3186-91. http://dx.doi. org/10.1097/00007632-200012150-00014

20. American Academy of Sleep Medicine. International classification of sleep disorders. 3rd ed. Darien, IL: AASM; 2014.

21. Clinical Guidelines on the Identification, Evaluation, and Treatment of Overweight and Obesity in Adults-The Evidence Report. Nationa Institutes of Health. Obes Res. 1998;6 Suppl 2:51S-209S. Erratum in: Obes Res. 1998;6(6):464

22. Pasquali L. Princípios de elaboração de escalas psicológicas. Rev Psiq Clin. 1998;25(5):206-13.

23. Bonin CD, Santos RZ, Ghisi GL, Vieira AM, Amboni R, Benett $\mathrm{M}$. Construction and validation of a questionnaire about heart failure patients' knowledge of their disease. Arq Bras Cardiol. 2014;102(4):364-73. http://dx.doi.org/10.5935/abc.20140032

24. Paine P, Pasquali L, Paulo Ede S, Bianchi AL, Solha AC. Psychometric properties of the Brazilian Health Locus of Control Scale. Psycho Rep. 1994;75(1 Pt 1):91-4

25. Cronbach J. Fundamentos da Testagem Psicológica. 6th edition. Porto Alegre: Artes Médicas; 1996.

26. Koller M, West K. Linguistic Validation Manual for Patient-Reported Outcomes (PRO) Instruments, By C. Acquadro, K. Conway, C. Girourdet \& I. Mear, MAPI ResearchTrust, Lyon, France, 2004,184 pp, ISBN: 2-9522021-0-9, price €70/\$90. Qual Life Res. 2005;14(7):1791 2. http://dx.doi.org/10.1007/s11136-005-5367-1

27. Felisbino MB, Steidle LJ, Gonçalves-Tavares M, Pizzichini MM, Pizzichini E. Leicester Cough Questionnaire: translation to Portuguese and cross-cultural adaptation for use in Brazil. J Bras Pneumol. 2014;40(3):213-21. http://dx.doi.org/10.1590/S180637132014000300003

28. Yang Y, Chung F. A screening tool of obstructive sleep apnea: STOP Bang questionnaire. Sleep Med Clinics. 2013;8(1):65-72. http:// dx.doi.org/10.1016/j.jsmc.2012.11.004

29. Luo J, Huang $R$, Zhong $X$, Xiao $Y$, Zhou J. Value of STOP-Bang questionnaire in screening patients with obstructive sleep apnea hypopnea syndrome in sleep disordered breathing clinic. Chin Med $J$ (Engl). 2014;127(10):1843-8.

30. Bille DJ, Bille-Hasselstrøm C, Petersen CG. Translation and validation of the Stop-Bang Questionnaire for obstructive sleep apnoea into Danish. Dan Med J. 2015;62(12):A5158.

31. Sadeghniiat-Haghighi K, Montazeri A, Khajeh-Mehrizi A, Ghajarzadeh $\mathrm{M}$, Alemohammad ZB, Aminian $\mathrm{O}$, et al. The STOP-BANG questionnaire: reliability and validity of the Persian version in sleep clinic population. Qual Life Res. 2015;24(8):2025-30. http://dx.doi. org/10.1007/s11136-015-0923-9

32. Alhouqani S, Al Manhali M, Al Essa A, Al-Houqani M. Evaluation of the Arabic version of STOP-Bang questionnaire as a screening too for obstructive sleep apnea. Sleep Breath. 2015;19(4);1235-40. http:// dx.doi.org/10.1007/s11325-015-1150-x

33. Tavares MG, Pizzichini MM, Steidle LJ, Nazario NO, Rocha CC Perraro MC, et al. The Asthma Control Scoring System: translation and cross-cultural adaptation for use in Brazil. J Bras Pneumol. 2010;36(6):683-92 